\title{
Small-scale energy storage for integration of renewable supplies with smart grids
}

\author{
M. McDonald ${ }^{1}$, L. Dilley ${ }^{1}$, M. E. Barber ${ }^{1}$, R. Mahler ${ }^{2}$, J. Adam ${ }^{1}$, \\ M. Wolcott ${ }^{1} \&$ A. Ford ${ }^{3}$ \\ ${ }^{I}$ Department of Civil and Environmental Engineering, \\ Washington State University, USA \\ ${ }^{2}$ Soil Science and Water Quality, University of Idaho, USA \\ ${ }^{3}$ School of Earth and Environmental Sciences, \\ Washington State University, USA
}

\begin{abstract}
Rapid expansion of renewable energy is occurring throughout the world due to national government financial incentives, state government mandates, and public perceptions regarding green energy. In the United States, wind power is the predominant source of renewable energy with cumulative installed capacity of over $60,000 \mathrm{MW}$ as of 2012. However, integration of renewable into existing grids or proposed micro- and smart- grids is expensive with the US National Renewable Energy Laboratory estimating costs to range from US \$3.5 to $\$ 5.0 / \mathrm{MWh}$ particularly since the unreliable nature of wind does not increase reliable generation capacity. Conventional generation facilities are therefore still needed to ensure demands can be met at all times.

Storage represents one of the grand challenges facing areas with large seasonal variations in energy supply and demand. Although a number of studies suggest that grid systems in large balancing areas could handle up to $20 \%$ renewable penetration without additional storage, recent evidence suggests the lack of storage requires negative pricing at the wholesale level during periods of high power, low demand. Furthermore, smaller micro- and smart- grids will benefit from improved flexibility brought on by increased storage.

While numerous studies and installations of large pump storage projects exist globally, the availability of large off-channel reservoir sites in the US is relatively limited. Investigation of smaller facilities $\left(<=150,000 \mathrm{~m}^{3}\right)$ would greatly improve utility in micro- and smart- grid systems. This study examined
\end{abstract}


the initial feasibility of a scenario involving small storage, high head. A model has been developed to examine the trade-offs between cost, size, power generation, water supply, and other environmental services.

Keywords: pumped storage hydropower, wind energy, off-channel storage, renewable energy, micro and smart grids.

\section{Introduction}

If every electricity facility was able to ramp production up and down on demand and if grid operators were able to reliably predict solar and wind conditions, integrating power supplies from renewable sources would pose little problem beyond economic considerations (Nelder [1]). However, since this is not the case, integration of multiple new electrical energy sources into existing grid infrastructure represents one of the primary challenges related to development of renewable energy supplies. While coveted as a clean energy source, renewable energy sources are inherently intermittent and unpredictable and often exhibit fast ramping rates as meteorological conditions change. Rapid development of renewable energy resources (e.g. wind, solar) over the past decade is forcing many electricity generation grids towards their safe and reliable operations limits because, as the percentage of renewable supply to peak demand increases, system flexibility becomes scarce. Furthermore, renewable energy policies throughout the United States and the rest of the world will likely lead to increased generation of wind and solar power into the foreseeable future. Integration of renewables into existing grids or proposed micro- and smart- grids is expensive with the US National Renewable Energy Laboratory estimating costs to range from US $\$ 3.5$ to $\$ 5.0 / \mathrm{MWh}$. Consequently, energy storage, either at generation sites or at strategic grid locations, is cited as one important step in facilitating the integration of renewable energy (Goodenough et al. [2], Yang and Jackson [3]).

Pumped storage hydropower (PSH) is an integral part of the energy grid world-wide and is considered to be an important part of a renewable energy structure (Levine [4]). As of 2010, Deane et al. [5] reported there were 300 PSH plants worldwide, with an installed generation capacity of $95 \mathrm{GW}$. Development of PSH originally occurred alongside inflexible generators, nuclear and coal specifically, for the purpose of providing flexibility and peaking power. Recent interest in the development of green energy, the implementation of Renewable Portfolio Standards (RPS), and market liberalization in the US and abroad have spurred new interest in PSH (Yang and Jackson [3]). Europe catalogs 7400 MW of proposed PSH, $2014 \mathrm{MW}$ of which is in Switzerland (Deane et al. [5]). In the US, 39 preliminary permits for PSH were filed in the US between 2005 and 2010, for a total of 33,000 MW of new pumped-storage (Hadjerioua et al. [6]).

While numerous studies and installations of large pump storage projects exist globally, the availability of large off-channel reservoir sites in the U.S. is relatively limited. The U.S. Department of Energy's Hydropower Program has only identified 5,677 sites across the entire US with acceptable undeveloped hydropower potential (USBR [7]). If fully developed, these sites could produce 
an estimated $30 \mathrm{GW}$ of additional power (about 40 percent of today's existing hydropower supply). However, investigation of smaller facilities $\left(\sim 150,000 \mathrm{~m}^{3}\right.$ and below) would greatly improve utility in micro- and smart grid systems. This study examined the initial feasibility of scenarios involving small storage, high head. Initial results are presented in this paper.

\section{Background}

Storage is needed to improve the efficiency of electricity operations. A typical electricity grid includes wires, substations, transformers, switches, meters, voltage sensors, and more that can transmit electricity over long distances. According to the U.S. Energy Information Agency, approximately 7\% of generated electricity is lost to transmission and distribution losses. Furthermore, the longer the distance between generation and use, the more potential for power outages due to downed power lines and the need for more infrastructure. While the U.S. electricity grid is very reliable, power outages are estimated to cost Americans $\$ 150$ billion each year with the potential for increased interruptions unless upgrades are made to the system. These issues, combined with integration of renewable energy sources, are where smart grids and microgrids come in. Smart grids use real-time, two-way communication technologies and computer processing to improve energy efficiency of these existing electricity grids (USDOE [8]). Microgrids are an interconnection of distributed energy sources (e.g. microturbines, wind turbines, fuel cells and photovoltaic systems) integrated with storage devices (e.g. batteries, flywheels and power capacitors) on low voltage distribution systems in so-called "Local Energy Networks" (see Figure 1). There are various microgrid configurations including: 1) consumer microgrid - single consumer demand, 2) community microgrid - multiple consumer demands, and 3) utility microgrid - supply resources on utility side with consumer interactions, utility objectives.

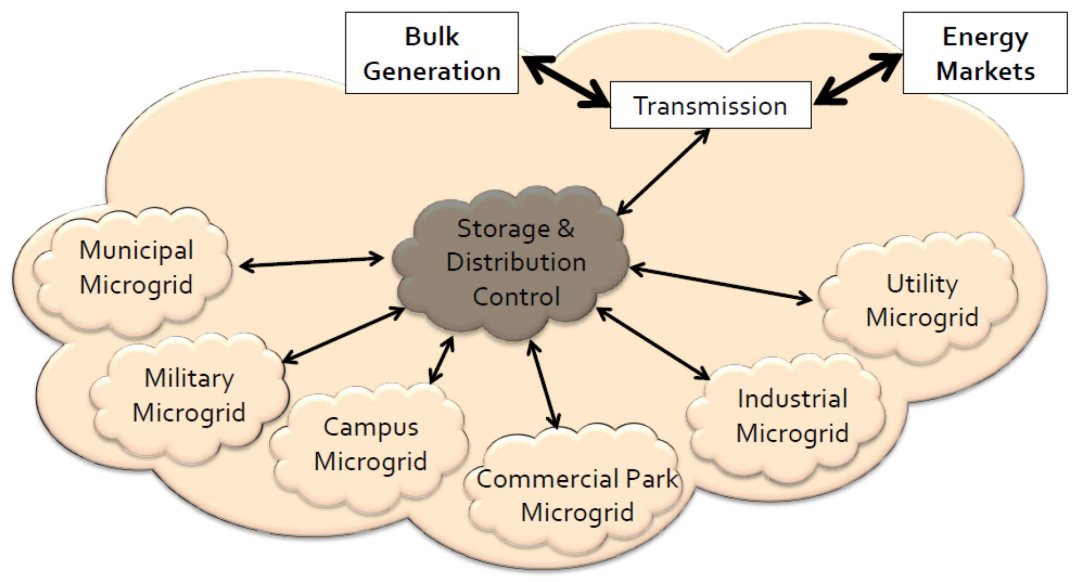

Figure 1: $\quad$ Essential nature of storage in microgrid arrays (after Bossard [11]). 
The critical component of future electrical grids will be its need to optimize energy delivery supplied from numerous sources. Smart grids and microgrids require energy storage systems to solve mismatch problems (Zamora and Srivastava [9]). The storage components need to evaluate not only the total energy produced but also the potential savings in reducing the need for other fixed load systems. For example, despite having two large hydroelectric facilities and investing heavily in the Nine Canyon Wind Project, Pratt [10] reported that Grant County Public Utility District (PUD) is also evaluating a \$511 million U.S.D. natural gas plant that would produce nearly $300 \mathrm{MW}$ of electricity to make up for projected short-falls in peak demands. This is due at least in part to the non-power constrains (NPC) placed on dam operations including fish spill from mid-April through August (39 to 61\% of total flow), reverse load factoring for five weeks beginning in mid-October, and protection level flows from November through mid-April. PSH can help by using electricity generated during reverse load factoring and evening discharges to produce more peak power.

The representative demonstration site for this study is located approximately $15 \mathrm{~km}$ (9 miles) southwest of Pullman, Washington originating at Wawawai Bay on the Snake River. The system would pull water from the river and deliver it to a storage facility located near the top of the grade 5,800 meters (3.6 miles) away from the site. The elevation changes from $225 \mathrm{~m}$ at the Bay to $740 \mathrm{~m}$ at the storage facility for a head difference of $515 \mathrm{~m}(1,690 \mathrm{ft})$. This location was chosen in part because it is similar to many other sites along the Snake River but also because there is potential to use the water to offset aquifer drawdown in the region to help off-set some of the costs.

We examined the impact of a small storage pond on the amount of power that could be generated. For the purpose of this study, it was assumed that all water returned to the stream although the environmental services provided to many small communities along the area for releasing the water into uphill streams and aquifers could help support operation. The head at this location was $515 \mathrm{~m}$ $(1,690 \mathrm{ft})$ which represents typical height differences along the Snake and Columbia River watersheds within the State of Washington.

\section{Methodology}

There are a number of design options for PSH systems. Figure 2 illustrates a hydraulic bypass option rather than a reversible pump-turbine unit allowing for separate pump and turbines which enables fast grid primary control and alleviates some problems with matching system efficiencies. However, this work assumed that either option could be implemented with ultimately cost and energy production the deciding factors. Nevertheless, the round-trip efficiency for both PSH systems was assumed to be $75 \%$ which is at the lower end of the reported 75 to $78 \%$ range (Eyer and Corey [12]). 


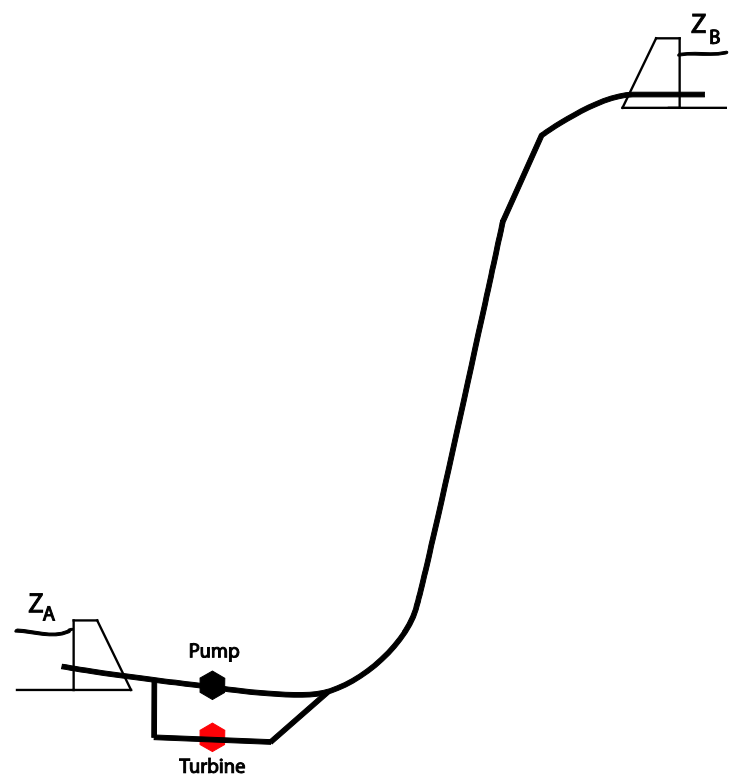

Figure 2: $\quad$ Schematic of hydraulic bypass PSH system.

The model used Bernoulli's Energy equation applied from the lower reservoir at $Z_{A}$ up to the upper reservoir $Z_{B}$ to examine the trade-offs between pipe diameter, required pressures, flow rate, pipe thicknesses, and system costs. The maximum pressure occurred on the positive side of the pump and included elevation head, friction losses, and minor losses.

The required pipe wall thickness $(\mathrm{t})$ is given by:

$$
t=\frac{\mathrm{P} * \mathrm{D}}{2(\mathrm{~S} * \mathrm{E}+\mathrm{P} * \mathrm{Y})}
$$

where $\mathrm{P}$ is pressure [psi], $\mathrm{D}$ is pipe diameter [inches], $\mathrm{S}$ is allowable tensile stress $[16,000$ psi by ASME standard for steel], E is the material quality factor set as 0.8 for steel $\mathrm{A} 139$, and $\mathrm{Y}$ is the wall thickness coefficient which is set equal to 0.4 for temperatures up to $38^{\circ} \mathrm{C}\left(100^{\circ} \mathrm{F}\right)$. The resulting thickness value is in inches.

The pipe pressure $(\mathrm{P})$ is found by examining the hydraulic grade line and substituting the head requirement into:

$$
P=\frac{S g * H}{2.31}
$$

where $\mathrm{H}$ is head [feet] and $\mathrm{Sg}$ is specific gravity.

The thickness of the pipe determines the weight per unit length. With U.S. steel prices ranging from $\$ 720$ to $\$ 900$ per ton, the impact can be significant. A $91.4 \mathrm{~cm}$ (36 inch) outside diameter (OD) pipe with a $6.35 \mathrm{~mm}(0.25$ inches) wall 
costs only half what a $12.7 \mathrm{~mm}$ ( 0.50 inch) pipe would cost thus saving over $\$ 725,000$ for the pipeline. For comparison purposes, steel prices of $\$ 750 /$ ton and $\$ 900 /$ ton were used in our analysis. Site excavation costs were estimated to be $\$ 7.50 /$ cubic yard from 2012 bid packages received by the Washington State Department of Transportation for various highway projects.

To evaluate the use of small scale storage in this hypothetical system, an algorithm was developed to calculate the effect of adding a PSH operation to a grid. In the algorithm, cost was minimized using a unit commitment approach to allocating generation between a baseload provider (referred to as "thermal") and a storage provider (PSH). The baseload is assumed to represent an aggregate set of generators that would be tasked with meeting $100 \%$ of demand at all times in the absence of storage. That is to say, the microgrid is islanded and there is no intertie between the modeled microgrid and the rest of the grid. Total cost included the cost to run the thermal equivalent generator, cost to pump water into the upper reservoir, and a large, nearly discontinuous, penalty for violating the volume constraints on the reservoir (which serves effectively as a constraint). Both the thermal generator and the PSH (in both pumping and generating mode) were allowed to operate continuously between zero and rated power, which is a significant operational simplification, and the ability of the generators to ramp up or down was not limited. The constraints, then, were that PSH power and Thermal power sum to the Demand Load, and that PSH power and Thermal power are less than or equal to their respective maximums in both pump and generating mode.

\section{Results and discussion}

This study found that incorporating PSH into a hypothetical microgrid can improve the system by reducing ramping rates and the number of ramping events, as well as setting baseload operating points at higher electrical efficiency. Figure 3 shows the result of adding a $154,000 \mathrm{~m}^{3}$ (125 acre- $\left.\mathrm{ft}\right)$ pond for PSH to existing baseload thermal generation. The model is designed so that when demand from the grid exceeds the thermal generation, the PSH generates the additional power. Conversely, when demand falls below thermal generation the PSH system pumps water to fill the pond thus using the unmet power supply from thermal. These results correspond to Case 5 in Table 1 below.

Setting the baseload to operate at a constant level is not a cost minimum from a fuel usage perspective. Improved fuel costs can be achieved by allowing the baseload to ramp down further during heavy load hours (HLH) and can be displaced by lower-cost pumped-storage generation. This behavior can be seen in Figure 3, although at a significantly reduced level from what would be required if baseload generation was the only generation available to meet demand.

Additionally, HLH and light load hours (LLH) pricing, based on winter rates in the Bonneville Power Authority 2014 proposed rate case, exhibited approximately a $10 \%$ spread, and were approximate $10 \%$ lower than the gas price used in the simulation. This spread is sufficient for the PSH to make a 


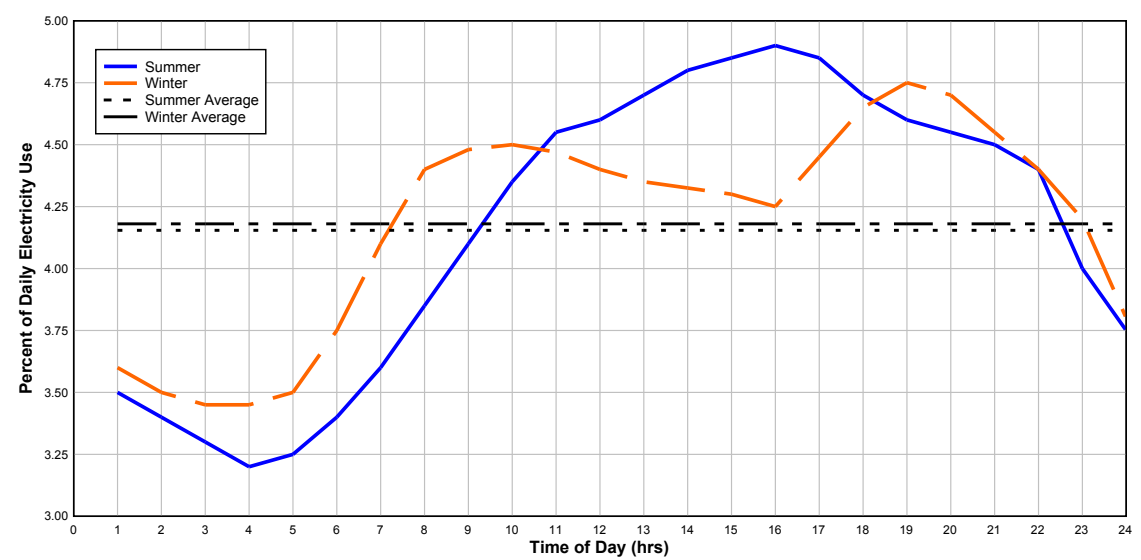

Figure 3: Diurnal electricity demand for U.S. (after Sailor and Lu [13]).

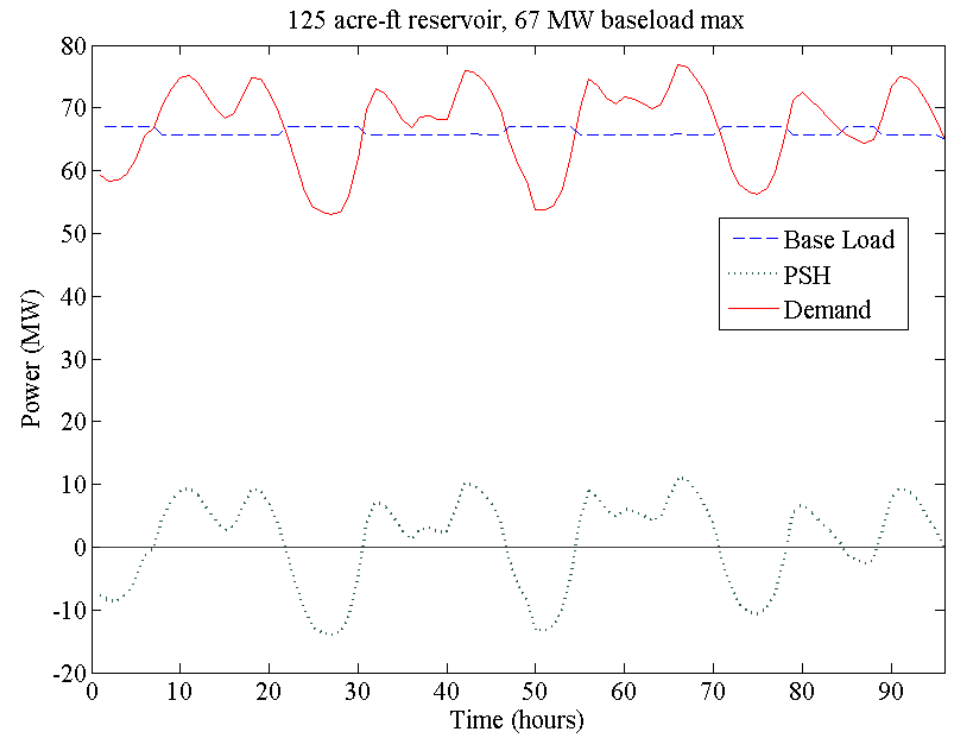

Figure 4: $\quad$ PSH pumping and generating schedule for a 4-day period.

small profit based on energy arbitrage alone at market prices, as well as to reduce fuel costs to the thermal generator. However, the total cost reduction is very modest - on the order of a few percent - and the real savings is in wear and tear as well as loss of efficiency in the baseload generation fleet. 
Table 1: Cost output from five design scenarios. Case 5 is depicted above in Figure 1 .

\begin{tabular}{|c|c|c|c|c|c|c|c|}
\hline & $\begin{array}{c}\text { Thermal } \\
\text { Max } \\
\text { Power }\end{array}$ & $\begin{array}{c}\text { Res. } \\
\text { Size }\end{array}$ & $\begin{array}{c}\text { Set } \\
\text { Storage } \\
\text { Profit }\end{array}$ & $\begin{array}{c}\text { Net } \\
\text { Thermal } \\
\text { Cost }\end{array}$ & $\begin{array}{c}\text { Fuel } \\
\text { Savings } \\
\text { to T }\end{array}$ & \multicolumn{2}{|c|}{ Variance T } \\
\hline MW & $\begin{array}{c}\text { acre- } \\
\mathrm{ft}\end{array}$ & $\$$ & $\$$ & $\%$ & $\mathrm{MW}$ & $\%$ \\
\hline $\begin{array}{c}\text { Base } \\
\text { Case }\end{array}$ & 95 & N/A & - & 296,220 & & 23.8 & $25 \%$ \\
\hline Case 1 & 80 & 125 & 29,983 & 292,370 & $1 \%$ & 39.0 & $49 \%$ \\
\hline Case 2 & 70 & 125 & 12,628 & 292,370 & $1 \%$ & 27.0 & $39 \%$ \\
\hline Case 3 & 70 & 150 & 13,131 & 291,600 & $2 \%$ & 13.7 & $20 \%$ \\
\hline Case 4 & 70 & 200 & 13,192 & 290,060 & $2 \%$ & 11.2 & $16 \%$ \\
\hline Case 5 & 67 & 125 & 8,758 & 292,370 & $1 \%$ & 2 & $3 \%$ \\
\hline
\end{tabular}

The preliminary results summarized in Table 1 demonstrate the ability of a small reservoir to reduce the amount of wear and tear on baseload generators at no additional operating (fuel) costs. In fact, even at a conservative overall efficiency of $75 \%$, the storage facility operated at a small profit based on energy prices alone.

The most dramatic result is that performance improvements are not particularly sensitive to reservoir size, as shown in cases 2, 3, and 4. By increasing the size of the reservoir nearly $100 \%$, the cost savings did not increase significantly, and the reduction in variance in the baseload generators improved by a few percent. The constraint on the storage generation output was loose enough that it was never the limiting factor, and ranged over the scenarios examined between 10 and $20 \mathrm{MW}$. The upper limit of the baseload generators relative to minimum and maximum power demand is the limiting factor in determining pump/generator size. The improvements in the system were most sensitive to the maximum power output of the baseload generator. By setting max output near the median load, the greatest system benefit was realized. 125 acre-feet was determined to be the lower practical limit on reservoir size in this study.

A range in piping costs was calculated based on the overland distance from the river to the storage pond site $(3.6 \mathrm{mi})$ and two pipe diameters. Corresponding pipe wall thicknesses were chosen based on the pressure on the positive side of the pump: 2 inches for a 6-foot diameter pipe and 1.5 inches for a 2-foot diameter. At $\$ 720$ to $\$ 900$ per ton for steel pipe, a range in cost was found to be approximately $\$ 2.5-10$ million. The tradeoff between each pipe diameter is the required head the pump must overcome to fill the pond. Smaller diameter pipe will cost less but will introduce more frictional head at a given flow rate, thus requiring a larger pump. On the other hand, large diameter pipe will cost much more but require a smaller pump for the flow rate due to lower frictional 
headloss. Excavation at $\$ 7.50$ /cubic yard equated to roughly $\$ 1.5$ million for the 125 acre-foot pond, but could vary significantly based on the site chosen.

Thus, installing water conduit is by far the largest factor in the capital costs associated with building a small PSH reservoir, making siting a significant economic consideration. In order to determine the feasibility of a high-head installation such as this one, additional energy production costs and construction costs must be determined. The PSH profit is not large enough to support large capital costs as is typical with traditional impoundment and reservoir developments, but when PSH profit or energy value is combined with savings to the micro grid and possible value associated with water supply, environmental services, and other ancillary benefits, PSH on this scale is likely to be feasible.

\section{Conclusions and recommendations}

Optimum use of renewable energy sources requires electricity storage to shift energy supply capabilities to energy demand windows. While research continues on many fronts to perfect energy storage options, PSH remains the most economical choice provided locations can be found. This initial analysis demonstrates the potential utility of PSH systems. These initial results demonstrate the ability of modest storage technologies to drastically alter the operating conditions of generation technologies, potentially for the better, and indicate that further study is needed.

Future versions of this simulation will expand the detail of the model proposed above to more accurately capture the operating constraints and economic tradeoffs between storage and dispersed generation sources. The first steps will be to more carefully model the costs and benefits of the microgrid to include the condition in which benefits are not monetized based on market prices but rather on internal grid operating priorities and that operating and maintenance costs are affected by changes in operating strategy. This step includes more specifically modeling the thermal or baseload generation technologies, which could include must-run technologies like micro-hydro or combined heat and power (CHP) systems, or intermittent technologies like wind and PV.

The economics of PSH would likely be improved if wholesalers could charge consumers a differential for peak and off-peak power consumption in the region but the abundance of inexpensive hydropower in the PNW somewhat diminishes the impact of even differential pricing. Idaho, Oregon, and Washington residential users paid approximately $\$ 0.083 / \mathrm{kWh}$ in 2010 compared to nearly $\$ 0.19 / \mathrm{kWh}$ average of New York and Connecticut. Simply put, even a $15 \%$ differential would only amount to a few dollars a month for most homeowners in the PNW which may not be enough to dramatically alter behavior. In the context of microgrid, it may be possible to use the concept of differential pricing to affect the consumption behaviors of local customers, whose decisions are based not only on price, but possibly on awareness of how their own microgrid functions. 


\section{Acknowledgements}

This work was partially supported by fellowships from the Hydro Research Foundation (funded by the US Department of Energy) and from support from the WSU Energy Systems Innovation (ESI) Center.

\section{References}

[1] Nelder, C. Why baseload power is doomed. Smart Planet. 2012. http://www.smartplanet.com/blog/energy-futurist/why-baseload-power-isdoomed $/ 445$.

[2] Goodenough, J.B., Abruna, H.D., and Buchanan, M.V., Basic research needs for electrical energy storage. U.S. Department of Energy, Office of Basic Energy Sciences, 2007. http://web.anl.gov/energy-storagescience/publications/EES_rpt.pdf.

[3] Yang, C.J., and Jackson, R.B. Opportunities and barriers to pumped-hydro energy storage in the United States, Renewable and Sustainable Energy Reviews, 2012, 15:839-844.

[4] Levine, J.G. Pumped hydroelectric energy storage and spatial diversity of wind resources as methods of improving utilization of renewable energy sources. Master of Science Thesis, College of Engineering and Applied Science, University of Colorado, Boulder, Colorado, 2003.

[5] Deane, J.P., Ó Gallachóir B.P., and McKeogh, E.J. Techno-economic Review of Existing and New Pumped Hydro Energy Storage Plant. Renewable and Sustainable Energy Reviews, 2012, 14:1293-1302.

[6] Hadjerioua, B., Bishop, N. et al. National resource assessment of Pumped Storage Hydropower (PSH). Oak Ridge National Laboratory. 2011, Publication ORNL/TM-2011/225.

[7] US Bureau of Reclamation. (USBR) Managing water in the west: hydroelectric power. 2005. U.S. Department of Interior, Power Resources Office, http://www.usbr.gov/power/edu/pamphlet.pdf

[8] US Department of Energy (USDOE). The smart grid: an introduction. http://energy.gov/sites/prod/files/oeprod/DocumentsandMedia/DOE_SG_B ook_Single_Pages\%281\%29.pdf

[9] Zamora, R., and Srivastava, A.K. Controls for microgrids with storage: review, challenges, and research needs. Renewable and Sustainable Energy Reviews, 2010, 14(7): 2009-2018.

[10] Pratt, C. Grant PUD considering \$511 million supplemental gas plant. Wenatchee World, 2010.

[11] Bossard, S. DOE perspective on microgrids. Advanced Microgrid Concepts and Technologies Workshop, U.S. Department of Energy, National Energy Technology Laboratory, 2012.

[12] Eyer, J. and Corey, G., Energy storage for the electricity grid: benefits and market potential assessment guide. A study for the DEO Energy Storage Systems Program. Sand2010-0815, Albuquerque, NM, 2010. 
[13] Sailor, D.J., and Lu, L. A top-down methodology for developing diurnal and seasonal anthropogenic heating profiles for urban areas. 2004. Atmospheric Environment, 38: 2737-2748.

[14] Auer, J., and Keil, J. State of the art energy storage systems. 2012. Deutsche Bank AG, ISSN 1612-314X, Dieburg, Germany. 